\title{
Environmental Compatibility Problem
}

National Cancer Institute

\section{Source}

National Cancer Institute. Environmental Compatibility Problem. NCI Thesaurus. Code C63209.

Problem associated with the surrounding conditions in which the device is being used such as temperature, noise, lighting, ventilation, or other external factors such as power supply. 